\title{
O papel dos líderes diante da pandemia de Covid-19
}

\section{The role of leaders in the face of the Covid-19 pandemic El papel de los líderes ante la pandemia de Covid-19}

\author{
Carlos Pernisa Júnior ${ }^{1, a}$ \\ carlos.pernisa@ufjf.edu.br | https://orcid.org/0000-0002-5003-0094 \\ ${ }^{1}$ Universidade Federal de Juiz de Fora, Faculdade de Comunicação. Juiz de Fora, MG, Brasil. \\ a Doutorado em Comunicação pela Universidade Federal do Rio de Janeiro.
}

\section{RESUMO}

A atuação de líderes de diversos países pode ser determinante no enfrentamento de uma pandemia, como a de Covid-19. De acordo com suas posturas, entrevistas e discursos, há maneiras diferentes de se encarar a crise de saúde e suas consequências em cada local afetado. Com o intuito de demonstrar como isso vem ocorrendo de modo mais efetivo, este artigo pretende analisar posturas, entrevistas e discursos de presidentes e primeiros-ministros ou chanceleres. Para um recorte que permita verificar melhor como alguns chefes de governo influenciam suas nações, foram escolhidos como exemplos Jacinda Ardern, da Nova Zelândia; Jair Bolsonaro, do Brasil; Angela Merkel, da Alemanha; e Donald Trump, dos Estados Unidos. A análise vai abranger um período específico do início da pandemia, levando em conta os meses de janeiro até abril de 2020.

Palavras-chave: Comunicação; Pandemia; Covid-19; Líderes; Atuação.

\section{ABSTRACT}

The performance of leaders of different countries can be decisive to tacke a pandemic, such as that of Covid-19. According to their postures, interviews and speeches, there are different ways of facing the health crisis and its consequences in each affected territory. In order to demonstrate how this has been happening more effectively, this article intends to analyse postures, interviews and speeches of presidents and prime ministers or chancellors. To make possible an analysis in detail observing how some heads of government influence their nations, we have chosen Jacinda Ardern, from New Zealand; Jair Bolsonaro, from Brazil; Angela Merkel, from Germany; and Donald Trump, from the United States. The analysis focuses on a specific period at the beginning of the pandemic, taking into account the months from January to April 2020.

Keywords: Communication; Pandemic; Covid-19; Leaders; Performance. 


\section{RESUMEN}

Las actuaciones de líderes de diferentes países pueden ser decisivas en el enfrentamiento de una pandemia, como la de Covid-19. Según sus actitudes, entrevistas y discursos, hay diferentes maneras de enfrentar la crisis de salud y sus consecuencias en cada territorio afectado. Para demostrar como eso está sucediendo de manera más efectiva, este artículo intenta analizar posturas, entrevistas y discursos de presidentes y primeros ministros o cancilleres. Para un análisis que posibilite ver con más detalles como algunos jefes de Gobierno influyen en sus naciones, fueron seleccionados Jacinda Ardern, de Nueva Zelanda; Jair Bolsonaro, de Brasil; Angela Merkel, de Alemania; y Donald Trump, de los Estados Unidos. El análisis abarca un período específico del inicio de la pandemia, teniendo en cuenta los meses desde enero hasta abril de 2020.

Palabras clave: Comunicación; Pandemia; Covid-19; Líderes; Actuación.

Contribuição dos autores:

Concepção e desenho do estudo: Carlos Pernisa Júnior.

Aquisição, análise ou interpretação dos dados: Carlos Pernisa Júnior.

Redação do manuscrito: Carlos Pernisa Júnior.

Revisão crítica do conteúdo intelectual: Carlos Pernisa Júnior.

Declaração de conflito de interesses: não há.

Fontes de financiamento: não houve.

Considerações éticas: não há.

Agradecimentos/Contribuições adicionais: não há.

Histórico do artigo: submetido: 07 set. 2020 | aceito: 19 fev. 2021 | publicado: 30 jun. 2021.

Apresentação anterior: não há.

Licença CC BY-NC atribuição não comercial. Com essa licença é permitido acessar, baixar (download), copiar, imprimir, compartilhar, reutilizar e distribuir os artigos, desde que para uso não comercial e com a citação da fonte, conferindo os devidos créditos de autoria e menção à Reciis. Nesses casos, nenhuma permissão é necessária por parte dos autores ou dos editores. 


\section{INTRODUÇÃO}

No contexto da pandemia de Covid-19, o papel dos governantes dos mais diversos países, suas posturas, suas declarações na imprensa e seus discursos em relação à disseminação do vírus merece uma maior atenção. A análise aqui proposta vai ser feita a partir de publicações em veículos de imprensa brasileiros e internacionais e também com base em dois discursos feitos logo no início da pandemia, em março de 2020, na Alemanha e no Brasil.

É relevante notar que todos os chefes de governo aqui abordados se destacaram na imprensa mundial por suas posições diante da pandemia de Covid-19. Daí o recorte da análise, que não se pretende exaustiva, visto que ainda, no momento da escrita deste artigo, essa doença é um problema mundial e não se tem um remédio ou vacina que se mostrem eficazes para a sua cura ou o seu controle. São significativos neste sentido os casos dos presidentes dos Estados Unidos, Donald Trump, e do Brasil, Jair Bolsonaro, por um lado, e os da chanceler alemã, Angela Merkel, e da primeira-ministra da Nova Zelândia, Jacinda Ardern, por outro.

A proposta é examinar com mais detalhe como a pandemia foi tratada no seu início e como isso parece refletir na condução da questão ao longo do ano de 2020, por países que se colocaram de modo diferente logo nas primeiras medidas tomadas para reduzir a disseminação do vírus. Nos casos estudados, mais especificamente, a propósito dos discursos de Angela Merkel, da Alemanha, e de Jair Bolsonaro, do Brasil, proferidos em março de 2020, haverá uma análise mais detalhada do seu conteúdo, tanto no contexto dos pronunciamentos durante sua própria gravação quanto diante da evolução do contágio do vírus nos dois países destacados.

\section{AS FALAS DOS LÍDERES}

O primeiro aspecto a ressaltar é que há claramente um descompasso entre as falas dos dois presidentes citados e a realidade com que eles tiveram de lidar. Os Estados Unidos, como um dos principais epicentros da doença, e o Brasil como o segundo país com mais casos da doença e poucas pessoas testadas, gerando ainda a desconfiança de que o avanço da Covid-19 em terras tupiniquins possa ser muito maior do que o divulgado, dado que muitas mortes não tiveram a confirmação da doença e muitas nem vão ser contabilizadas (MARINS; AMORIM; MATTOS, 2020).

Já Alemanha e Nova Zelândia estão no polo oposto, tomadas como exemplares no tratamento da pandemia. Angela Merkel teve sua postura reconhecida em seu país até por partidos de oposição (CHAZAN, 2020). Jacinda Ardern também obteve grande apoio popular em função da sua atuação diante do coronavírus (REUTERS, 2020).

Observando com mais detalhes esse quadro, Trump e Bolsonaro tiveram reações semelhantes com relação à doença. Ambos começaram dizendo que era uma gripe comum e que seria controlada com facilidade. Depois, com o avanço dos casos de pessoas contaminadas e o maior número de mortes, tiveram que mudar o discurso, mas disseram que o isolamento social não deveria ser a melhor medida. E ainda sobre o distanciamento social, disseram estar preocupados com a economia, complementando que seus países não poderiam ficar paralisados.

A principal diferença é que Trump não se colocou sempre na posição de alguém que desafia a ciência e os seus próprios ministros para lidar com a pandemia, enquanto Bolsonaro teve atitudes de quem não parece estar levando a sério a evolução da doença, participando de atos nas ruas, cumprimentando pessoas e até mesmo promovendo aglomerações com a sua presença. Até para anunciar que não estava com a Covid-19 - e, depois, que estava - foi bastante contraditório em suas falas e atuações. Trump apoiou a estratégia de isolamento social, após um tempo em que havia negado a importância da doença, apesar de não dar um 
bom exemplo em termos do que foi aconselhado em relação ao uso de máscaras. Chegou a apoiar essa ideia, mas não as usou sempre, algumas vezes desdenhando dessa e de outras indicações da Organização Mundial de Saúde (OMS), com a qual entrou em sérias desavenças, retirando inclusive o apoio dos Estados Unidos à instituição.

As estratégias dos dois para lidarem com a pandemia na questão da comunicação colocam em dúvida o que deve ser realmente feito pela população. "Quando vemos esse tipo de inconsistência e (declarações) questionando autoridades ou a comunidade científica, é difícil para pessoas normais, como nós, saber quem devemos escutar", diz Jeremy Youde, especialista global em políticas de saúde e reitor da Escola de Humanidades da Universidade de Minnesota, em Duluth (GIL, 2020). "Não sabemos o que devemos fazer. Devo ir ao supermercado ou não? Devo ir ver minha mãe idosa ou devo deixar essa visita para outra hora?” (GIL, 2020). "É importante ter uma comunicação consistente e transmitir às pessoas a realidade e o que podemos enfrentar", destaca Youde (GIL, 2020).

Youde se refere a Trump, mas o mesmo pode ser dito de Bolsonaro, que também entrou em rota de colisão com o seu ex-ministro da Saúde, Luiz Henrique Mandetta, exatamente por mostrar esse comportamento errático em relação ao enfrentamento da doença (MANDETTA..., 2020).

Entre as frases pinçadas das falas de Donald Trump (GIL, 2020), algumas se destacam: "Tudo está sob controle" - 22 de janeiro, um dia após o primeiro caso de Covid-19 ter sido confirmado no Estado de Washington. "Muitas pessoas pensam que desaparecerá em abril com o calor. À medida que o calor chegar. Desaparecerá em abril” - 10 de fevereiro, com 11 casos da doença confirmados. Os Estados Unidos estão "desenvolvendo rapidamente uma vacina" contra o coronavírus - 26 de fevereiro. Logo depois, o diretor do Instituto Nacional de Alergia e Doenças Infecciosas do governo, Anthony Fauci, reconheceu que um antígeno levará mais de um ano para ficar pronto (GIL, 2020).

Claramente, nem Trump nem Bolsonaro levaram a doença a sério desde o início e não souberam lidar com ela, colocando Estados Unidos e Brasil em situação de risco por não abordarem o problema da maneira correta e não fazendo uma comunicação eficaz para a população. Além disso, há uma falta de empatia com a própria população na fala dos dois sobre o vírus. E tanto Trump como Bolsonaro tentaram desqualificar a ciência e fizeram declarações, no mínimo, arriscadas, defendendo, por exemplo, o uso de cloroquina para curar os doentes de Covid-19 ou entrando em atrito com as autoridades sanitárias, no caso dos Estados Unidos, com Anthony Fauci e, no do Brasil, com Luiz Henrique Mandetta e Nelson Teich, ex-ministros da Saúde.

A ideia de uma comunicação consistente, transmitindo às pessoas a realidade e com um senso de importância do papel de destaque que tem, deve ser creditada ao discurso da primeira-ministra alemã, Angela Merkel (ALEMANHA..., 2020). Em 18 de março de 2020, ela se dirigiu à nação alemã para explicar como seria a atuação do governo no enfrentamento do vírus e como ela via a importância da atuação de cada um dos cidadãos do país. Este foi o primeiro pronunciamento em rede nacional pela TV feito pela chanceler Angela Merkel, durante 14 anos como governante, para não falar de seus discursos de celebração do Ano Novo.

Merkel fez questão de dizer claramente que a doença era grave e que todos deveriam levá-la a sério. Não inventou culpados nem quis trazer alguma cura milagrosa. Não colocou o seu governo fora do problema, mas trouxe o cidadão alemão para junto dela no enfrentamento do vírus. Destacou o tamanho do desafio e chegou a compará-lo à Segunda Guerra Mundial. No entanto, não fugiu da responsabilidade de chefe de Estado. Sua fala tornou-se um exemplo de como se portar e como se comunicar com a nação, colocandose inclusive na mesma situação de todos, afastados das famílias e das atividades cotidianas por conta do isolamento social. 
Jacinda Ardern obteve uma aprovação bastante destacada no enfrentamento da pandemia de Covid-19. A primeira-ministra da Nova Zelândia foi, no mínimo, ousada ao dizer que pretendia "eliminar, não apenas conter o vírus" (MENON, 2020). O país foi fechado por algumas semanas e suas fronteiras mantiveram-se, depois, com muitas restrições para a entrada de pessoas em seu território, composto de ilhas no Pacífico Sul, o que facilita bastante a política de enfrentamento adotada pelo governo local. A comunicação é colocada como algo bastante importante nesta política - não por acaso, pois a primeira-ministra se formou em Estudos de Comunicação, Ciências Políticas e Relações Públicas, em 2001, na Universidade de Waikato.

Ardern coloca a questão humana como fundamental para que o coronavírus seja enfrentado e conseguiu fazer uma quarentena de sete semanas com muito apoio popular para poder dizer que a Covid-19 foi eliminada na Nova Zelândia em junho de 2020.

Bolsonaro, por sua vez, em seus comentários sobre a doença se referiu a ela como "uma gripezinha" (PRONUNCIAMENTO..., 2020) e disse que havia uma "histeria" (GOMES, 2020) diante da pandemia. Sobre o número crescente de mortes no Brasil, no dia 20 de abril de 2020, ele fez o seguinte comentário: “Eu não sou coveiro, tá?" (GOMES, 2020). Já em 29 de abril, uma outra frase do presidente se destacou. Ao ser indagado sobre o número de mortos no país ter ultrapassado o da China, Bolsonaro rebateu: "E daí? Lamento. Quer que eu faça o quê?” (VEJA..., 2020). Foram várias as declarações feitas por ele durante a pandemia, muitas claramente nessa linha negacionista (VEJA..., 2020).

Existe a possibilidade de que os dois presidentes, Bolsonaro e Trump, tenham uma tática de falar para o seu eleitor, sempre pensando num contexto politico-eleitoral. A ideia é fazer com que esse eleitor mantenha a confiança no seu líder e que a percepção seja de que tudo vai terminar bem, como nos episódios da "gripezinha" (PRONUNCIAMENTO..., 2020) ou de que tudo está sob controle, numa estratégia que é chamada de 'campanha permanente'. Tanto Trump quanto Bolsonaro utilizam-se dela para manter-se no poder e também para mobilizar partidários em uma eterna disputa eleitoral que deve se prolongar para além do pleito propriamente dito (CIOCCARI; PERSICHETTI, 2019).

Os dois também costumam se dirigir aos seus eleitorados e seguidores via redes sociais, notadamente o Twitter, como forma de driblar a imprensa convencional e tentar entrar em contato direto com os seus partidários, sem a mediação dos meios de comunicação tradicionais (BRANT, 2018). Bolsonaro também tem se utilizado de lives feitas no período de seu governo, pelo seu canal no YouTube, sempre em um dia específico da semana, às quintas-feiras, como forma de se dirigir a seu público mais fiel (FREIRE, 2021).

Esse tipo de fala entre os próprios eleitores e apoiadores reforçaria a necessidade de apoio e de que o líder sabe o que está fazendo. No entanto, essa estratégia nem sempre vai dar certo. Isso depende de um reforço de um discurso em que há um inimigo e que todos devem estar mobilizados para lutar contra ele. Trump tem alguns: os imigrantes; os chineses; a OMS. Bolsonaro tem o PT e Lula; os comunistas; a classe política - em que coloca também o Supremo Tribunal Federal.

Nos discursos dos dois presidentes, o reforço de que o inimigo precisa ser combatido é sempre feito. Como o vírus não é um inimigo visível e nem pode ser combatido com palavras, torna-se algo muito mais difícil de se controlar e um problema para os dois.

Apesar de tentarem atribuir o problema da pandemia aos chineses, à OMS ou até aos comunistas segundo o ministro das Relações Exteriores brasileiro Ernesto Araújo (MINISTRO..., 2020) - não há muito espaço para que as pessoas simplesmente aceitem isso como um fato. Ainda que tenhamos um cenário repleto de notícias falsas e de pós-verdade, onde as pessoas acreditam no que querem e não no que pode ser provado, os partidários de Trump e Bolsonaro não podem ignorar as muitas mortes nos dois países. Não dá para colocar a culpa de todas elas no comunismo e na OMS. 


\section{DOIS DISCURSOS E SUAS VISÕES DE MUNDO}

Dois discursos separados por alguns dias de diferença e também proferidos em continentes diferentes. Duas posturas, duas visões. O pronunciamento, pela televisão, de Angela Merkel, chanceler federal alemã, aconteceu em 18 de março de 2020 (O DISCURSO..., 2020) - e alguns de seus destaques estarão nas falas citadas nas páginas seguintes. O de Jair Bolsonaro, presidente brasileiro, foi feito em 24 de março de 2020 (PRONUNCIAMENTO..., 2020) - também alguns de seus destaques estarão nas falas citadas nas páginas seguintes.

Como entender esses discursos? Como é possível percebê-los de uma forma que não seja apenas olhar para o que está dito em cada um deles? Essa é a motivação deste texto. A busca de alguma indicação que vá além do que está nas palavras, até porque esses discursos foram proferidos no âmbito televisivo e também difundidos pela internet. As visões sobre eles não podem ser restritas a alguns aspectos. Assim, a postura é investigar o que está visível, mas também algumas intenções que não ficam de todo esclarecidas pelo olhar.

Primeiro, é preciso entender que um pronunciamento à nação, feito pela autoridade máxima do país, tem um destaque midiático muito maior do que qualquer outra maneira de se comunicar vinda de um governo. Esses pronunciamentos são feitos, geralmente, por cadeias de rádio e televisão, com todos os veículos de massa transmitindo-os ao vivo. Ainda podem contar com sua divulgação pela internet e por outros canais possíveis nos dias atuais, como redes sociais ligadas ao próprio governo. Dito isso, entende-se que não se pode banalizar o seu uso e nem se pretender que as pessoas achem que o conteúdo do que foi exposto não deva ser levado a sério.

Um ponto crucial sobre o caso alemão. Como já dito, esse foi o primeiro pronunciamento em rede nacional pela TV feito pela chanceler Angela Merkel durante 14 anos como governante, se não forem considerados seus discursos de celebração do Ano Novo. Daí o reforço de algo que não é banal. Merkel se referiu a ele como uma maneira ‘incomum' de se dirigir à nação. Mais um motivo para atrair a atenção do público. Cerca de 30 milhões de pessoas ouviram e viram o discurso pela TV (CHAZAN, 2020).

Assim, os dois pronunciamentos de março de 2020 podem ser entendidos como momentos importantes no enfrentamento do coronavírus pelos dois países. A Alemanha estava vivendo a aflição do continente europeu, com muitos casos de Covid-19 na Itália, Espanha e França. O Brasil ainda começava a ter os seus primeiros casos de pessoas contaminadas, e o número de mortes passava de dez no dia do pronunciamento do presidente da República.

Brasil e Alemanha são países bastante diferentes, e a comparação dos dois discursos pode parecer inválida se for levada em conta essa diferenciação. No entanto, observar as falas dos líderes das duas nações pode ser útil para entender um pouco melhor a situação de enfrentamento do vírus por cada qual. Também é relevante para um estudo de comunicação, que se leve em conta o cenário atual. Merkel não é uma líder que esteja numa campanha permanente, até porque não deve ser novamente candidata, já que fez o anúncio ainda em 2018 confirmando que não tentaria a reeleição (MÜLLER, 2018). Bolsonaro, pelo contrário, mantém-se num ritmo de quem ainda disputa uma eleição, mesmo que tenha ganho a mais recente, pois o foco, ainda em 2020, é a reeleição em 2022.

Em termos de estratégia de comunicação, esta intenção de continuar ou não à frente do governo pode afetar a condução das ações de um líder. Há ainda que se pensar em relação ao fato de que Merkel, na Alemanha, é chanceler desde 2005, estando em seu quarto mandato consecutivo. Ou seja, os alemães sabem bem como ela é e o que pretende como governante. Já Bolsonaro, apesar do longo tempo em que está na política, quase 30 anos, apresentou-se na campanha eleitoral como alguém que está fora deste campo. Há ainda a questão de que pouco fala sobre seus planos e propostas, deixando muitas vezes de dar explicações, 
dizendo que os seus ministros e secretários é quem vão dar conta disso. Paulo Guedes, por exemplo, é quem daria as respostas sobre economia, sendo que ele, Bolsosnaro, não se intrometeria nesse aspecto.

Esse tipo de colocação demonstra que há uma vantagem de Merkel na hora de se dirigir à nação que já a conhece bem como chanceler. Bolsonaro é presidente há pouco tempo e também parece fazer questão de dizer que não é ele o responsável pela condução de assuntos relevantes de seu governo.

Dado esse quadro geral, há que se pensar nas estratégias de cada um para enfrentar a pandemia. A Alemanha de Merkel em momento nenhum deixou de encarar a questão como algo muito sério. Já o Brasil não teve a mesma postura. Isso se reflete claramente nos dois discursos. Entre eles se passaram seis dias, menos de uma semana. O problema é que esse vírus se dissemina rapidamente, e uma semana pode ser um tempo bastante longo.

Indo diretamente às mensagens, Merkel tenta fazer um retrato do que estava acontecendo e do que estava por vir na Alemanha naquele 18 de março de 2020. No país havia, naquele dia, 28 mortes pelo vírus confirmadas e mais de 12 mil casos de contaminação (CORONAVÍRUS..., 2021). A situação não era tão grave como na Itália, epicentro da doença naquele momento, com mais de 35 mil infectados e quase três mil mortos. Mesmo assim, a chanceler alemã não fez um discurso para dizer que a Alemanha se safaria daquela situação de maneira tranquila, apesar de dizer claramente que o sistema de saúde do país era um dos melhores do mundo e que a nação poderia ser bem-sucedida no combate ao vírus. "A Alemanha tem um excelente sistema de saúde, talvez um dos melhores do mundo. Isso nos dá confiança. Mas nossos hospitais ficariam completamente sobrecarregados se tantos pacientes com infecções severas causadas pelo coronavírus fossem admitidos em um tempo tão curto." (O DISCURSO..., 2020).

Merkel alertou para os desafios que deveriam ser enfrentados, já no início de sua fala. Ela ressalta mais à frente que a situação era muito grave. A chanceler não esconde o problema e os desafios para vencê-lo. E faz um importante alerta aos cidadãos alemães: "Deste modo, deixem-me dizer: isto é sério. Levem a sério também." (O DISCURSO..., 2020). O tom do discurso é esse: a gravidade do problema e a importância de se entender isso para que o país pudesse enfrentá-lo da melhor maneira possível. No entanto, Merkel vai além. Diz que está nas mãos dos cidadãos a melhor forma de resolver a questão.

O discurso é um chamamento à nação, uma maneira de mostrar à população que a situação só vai ser resolvida com a ação de todos, de modo conjunto. Não dá espaço para outras possibilidades, nem faz qualquer tentativa de minimizar a gravidade do problema. Há claramente a estratégia de unir o país sob um discurso comum. Entretanto, Merkel não fala como um general à frente de um exército indo para o campo de batalha. É muito mais uma líder que tenta se aproximar das pessoas e mostrar sua preocupação para com elas.

"Evidentemente, em uma situação como esta, cada um de nós está repleto de perguntas e preocupações sobre como seguir em frente." (O DISCURSO..., 2020). E também: "Nós podemos aceitar as limitações atuais e cuidar uns dos outros.” (O DISCURSO..., 2020). O uso da primeira pessoa do plural traz a inclusão, a postura de uma líder que também está vivendo o mesmo problema e que entende que o apoio e a empatia podem também fazer diferença, que a questão não é só de combate ao vírus, mas também de humanidade, de se sentir próximo do outro.

O outro dado relevante, principalmente num estudo sobre comunicação, é a parte em que Angela Merkel fala da importância de se comunicar bem com a população. Neste ponto, há uma questão fundamental. Todo o esforço alemão para o enfrentamento da pandemia poderia ser inútil se as ações adotadas pelo governo não fossem "compreensíveis". (O DISCURSO..., 2020). Merkel alerta: "Isto faz parte de uma democracia aberta: que nós também tomemos decisões políticas transparentes e as expliquemos. Que nós justifiquemos e comuniquemos nossas ações o melhor possível de modo que elas sejam compreensíveis.” (O DISCURSO..., 
2020). E, para isso, as decisões políticas deveriam ser transparentes e explicadas. A consciência disso pode ser o que determina como será o comportamento de uma população diante de um grande desafio.

O discurso de Merkel foi contundente, em cerca de 12 minutos no total, e tentou demonstrar o que o governo alemão estava pensando e como queria que fosse a atitude de todos para enfrentar o coronavírus. Não havia espaço para mágicas, promessas ou enganações. Foi direto e incisivo. O tom foi o de que a ameaça do vírus era real e deveria ser levada a sério. Todos teriam que estar conscientes disso, e a situação só melhoraria se cada um entendesse isso e agisse em conjunto com o restante da população, não exatamente como em uma ação de guerra, mas dando apoio e solidariedade.

Essa síntese do discurso pode ser analisada também em relação ao tom da chanceler, que não se exalta e nem se faz de distante. Sua fala é tranquilizadora em vários momentos, mas não é banal nem vacilante. Há pontos em que a dureza de postura é mais necessária, e a voz se eleva um pouco para marcar ou enfatizar uma frase ou uma palavra. O discurso se mostra necessário e unificador.

Com relação ao discurso do presidente brasileiro, há que se notar outras questões. Já se sabe que Bolsonaro não é uma pessoa muito hábil ao ter que ler textos prontos (POLITO, 2019a). Tem dificuldade com a pronúncia de diversas palavras e com a clareza de muitas delas (POLITO, 2019b). Mostra-se quase sempre desconfortável em pronunciamentos e percebe-se que ele está lendo o que tem para dizer. Isso já coloca o presidente brasileiro em uma situação desfavorável quando há necessidade de se dirigir à nação como um todo.

Normalmente, ele se sente melhor falando para uma plateia cativa que fica sempre em frente do Palácio do Planalto, aguardando para vê-lo e poder fazer alguma foto com ele. Ali, ele se solta e acaba sendo mais espontâneo, o que não quer dizer que tenha mais facilidade em se fazer entender, pois há sempre alguma pergunta, principalmente por parte da imprensa, que o desconcerta e faz com que pare de falar ou se irrite e tome atitudes intempestivas. Também fica mais à vontade em lives, onde sabe que conta com uma plateia que lhe é mais favorável e também sempre tem a seu lado pessoas que estão mais próximas, de sua convivência, muitas vezes (FREIRE, 2021).

Em alguns momentos, parece querer fazer com que a situação lhe seja favorável, invertendo lógicas e usando tiradas que lhe são muito peculiares para garantir vantagens em suas falas, quase sempre mais curtas e em caráter mais contundente (LAGO, 2018). Porém, isso é muito complicado em falas mais longas, como as feitas nos discursos transmitidos por cadeias de rádio e televisão.

Dito isso, a situação no Brasil em 24 de março de 2020, dia do pronunciamento de Bolsonaro, era a de 46 mortos e pouco mais de dois mil casos de pessoas contaminadas confirmados (CORONAVÍRUS..., 2021). Diferente da Alemanha, o número de casos no país era baixo, mas o de mortos nem tanto. A suspeita de subnotificações é um problema a mais a ser enfrentado quando se fala em Covid-19 no Brasil.

Bolsonaro tem um discurso bem característico. Em cerca de quatro minutos e meio, ele fala como se ainda estivesse em campanha para a sua eleição (PAULA, 2019). Esse não é um aspecto que seja exclusivo dele. Há quem fale em campanha permanente, e os exemplos são muitos no Brasil (FERRARI; OLIVEIRA; MARTINS; CHAIA, 2017) e fora daqui, com o presidente dos Estados Unidos, Donald Trump, sendo um dos mais destacados nesse caso (LEMOS, 2017).

Com isso, há que se atentar para dois níveis de discurso no caso de Bolsonaro. Um, em que tenta ser um presidente de todo o país e que fala para a nação, indistintamente, e outro, em que se dirige diretamente a seus seguidores, aqueles que o seguem como a um líder - de certo modo até religioso - e não parecem ter olhos para perceber falhas ou problemas no governo. No discurso em questão, Bolsonaro parece se dirigir muitas vezes a esse público fiel e, com menos frequência, ao povo brasileiro como um todo.

Alguns exemplos são claros. Pode-se destacar a fala quase no início do discurso: "Mas, o que tínhamos que conter naquele momento era o pânico, a histeria. E, ao mesmo tempo, traçar a estratégia para salvar vidas e 
evitar o desemprego em massa. Assim fizemos, quase contra tudo e contra todos" (PRONUNCIAMENTO..., 2020). Um presidente e seu governo contra tudo e contra todos é algo que soa estranho, já que o eleito para o cargo estava há pouco mais de um ano no poder e que, notadamente, o primeiro ano de governo costuma ser favorável ao seu ocupante (AGÊNCIA O GLOBO, 2019).

O presidente brasileiro enfrentou uma crise governamental bastante severa em seu primeiro ano de mandato, mas a reação da população foi maior depois de suas posturas mais conservadoras aparecerem com mais força. Neste discurso, por exemplo, ele traz alguns desses pontos:"O que se passa no mundo tem mostrado que o grupo de risco é o das pessoas acima dos 60 anos. Então, por que fechar escolas? Raros são os casos fatais de pessoas sãs, com menos de 40 anos de idade. $90 \%$ de nós não teremos qualquer manifestação caso se contamine." (PRONUNCIAMENTO..., 2020).

Isso foi, provavelmente, muito mal visto pela população que já estava em quarentena em várias cidades do país e viam a necessidade de um isolamento social para proteger vidas, e também observando que pessoas são infectadas, em qualquer idade, e podem passar o vírus para outras, que seriam dos chamados 'grupos de risco' - maiores de 60 anos e com outras comorbidades que permitiriam a ação mais violenta da doença.

A preocupação do presidente não pareceu ser, em nenhum momento, com o enfrentamento sério do vírus, tanto que chegou a falar em "gripezinha" e "resfriadinho" (PRONUNCIAMENTO..., 2020). Ao contrário, o discurso quase sempre se voltava para a necessidade de se preocupar com a economia e com a normalidade do país.

Há quem diga que nunca mais voltaremos a uma normalidade (VEGA, 2020). E, mesmo para quem aborda a ideia de uma possível volta à normalidade, isso não será fácil e nem rápido (DRAUZIO..., 2020). Assim, a fala do presidente, dizendo que a Covid-19 brevemente passará soa falso, e não porque foi dita em março, quando a pandemia ainda não tinha muita força no país, mas por estar descolada da realidade. A população com medo e com poucas respostas, e o presidente falando em soluções fáceis e a curto prazo.

Certamente, muita gente acreditou no discurso de Bolsonaro. Muitos defenderam a importância da preservação dos empregos e da normalidade da ida de crianças à escola. No entanto, mesmo o então ministro da Saúde, Luiz Henrique Mandetta, apontava para uma direção diferente da do presidente. Isso ficou claro mais à frente, quando foi demitido do cargo. No discurso, em março, Bolsonaro chegou a elogiar sua conduta. Menos de um mês depois, em 16 de abril, Mandetta estava fora do governo (MAZUI, 2020).

Bolsonaro queria que Mandetta adotasse uma postura diferente e que apoiasse o relaxamento do isolamento social e também incentivasse a abertura do comércio nas cidades e o uso de medicamentos sem comprovação para conter o vírus. O ministro não cedeu e ficou de fora do governo. A população, em grande parte, deu apoio ao agora ex-ministro e não ao presidente (DEMISSÃO..., 2020).

Essa postura mostra como o governo brasileiro enfrenta a crise do coronavírus. Enquanto Merkel apresenta uma posição de seriedade diante do problema, Bolsonaro não o faz e ainda questionou algumas evidências ou tratou de descobrir fórmulas pouco convencionais para o enfrentamento da doença. Ele disse que o Brasil não era a Itália, um país com maioria da população idosa - mas o vírus no Brasil atinge a população mais jovem também, e isso já em um período próximo à data do discurso (AGRELA, 2020) - e que o clima do país interferiria a nosso favor - o que também foi questionado na época (INGRID, 2020).

Outra fala do presidente que não foi bem aceita diz respeito ao tratamento da doença. Bolsonaro fez uma defesa do uso da cloroquina - como também já havia feito o presidente dos Estados Unidos, Donald Trump -, mas não havia evidências de que o remédio fosse mesmo eficaz (ROSSI, 2020).

Enquanto Angela Merkel adotou um tom de união nacional para o enfrentamento da doença, quase sempre longe de uma postura bélica, Bolsonaro, afeito à militarização do seu governo, já dava um tom diferente. Fala de "planejamento estratégico de combate ao vírus", de "linha de frente" e de que "venceremos 
o vírus e nos orgulharemos de estar vivendo neste novo Brasil" (PRONUNCIAMENTO..., 2020). O tom ufanista, comum ao brasileiro em geral, também deve ser aqui salientado.

Bolsonaro não procurou unir a nação, como até tentou demonstrar no final do discurso: "Estamos juntos, cada vez mais unidos, Deus abençoe nossa pátria querida."(PRONUNCIAMENTO..., 2020).No restante de sua fala, poucas vezes se dirige à nação como um líder de todos, com uma preocupação sincera com a população do país. Nem faz uma saudação inicial a ela, vai direto ao discurso. Trata do vírus como algo que não vai ter importância, pois passará em breve e vai ser vencido pelo país, mas não se sabe como e nem com que medidas. E fala de si próprio, como alguém com "histórico de atleta" (PRONUNCIAMENTO..., 2020), se por acaso fosse infectado, mas não da população em geral, que talvez não tenha esse mesmo preparo físico.

No que diz respeito à sua postura em relação à comunicação, ela é bem falha. Se Merkel diz textualmente que as pessoas têm que compreender o que o governo diz, Bolsonaro prefere atacar a imprensa e dizer que esta mudou, felizmente, sua postura de um dia para o outro: "parte da imprensa mudou seu editorial: pedem calma e tranquilidade. Isso é muito bom. Parabéns, imprensa brasileira. É essencial que o equilíbrio e a verdade prevaleçam entre nós.” (PRONUNCIAMENTO..., 2020). Isso não facilita em nada uma ação comum de toda a nação para enfrentar a situação.

Não se trata de uma "verdade prevalecer" (PRONUNCIAMENTO..., 2020), mas de medidas claras e que possam ser entendidas por todos para enfrentar o problema. Se Bolsonaro elogia Mandetta e a imprensa, ele acaba por dizer também que está em franca divergência com os dois. Mandetta tentando manter o isolamento social, e o presidente dizendo que isso é um exagero, sem citar o ministro, mas colocando a culpa em governadores e prefeitos. Já a imprensa mudar de tom quer dizer que ela estava, até o dia anterior: "na contramão [] [difundindo] exatamente a sensação de pavor [ ] para que uma verdadeira histeria se espalhasse pelo nosso país". (PRONUNCIAMENTO..., 2020). O que mostra que não há uma posição clara de Bolsonaro no caso em questão. Ele não parece ter a dimensão de sua importância e de suas palavras como chefe da nação.

Bem diferente é a postura de Merkel, que se mostra como uma líder preocupada com o seu povo, mostrando estar a seu lado e enfrentando a situação junto, como alguém que também sofre. Ela está longe daquele protótipo de atleta do presidente brasileiro, não se coloca como possível vítima, mas também não deixa de atentar para que todos estão vivendo a mesma situação, como já citado anteriormente. "Eles [os pacientes] não são apenas números abstratos em uma estatística, mas sim um pai ou um avô, uma mãe ou uma avó, um companheiro. Eles são pessoas. E nós somos uma comunidade em que cada vida e cada pessoa importa." (O DISCURSO..., 2020).

Merkel também se coloca ao lado da ciência e de especialistas de seu governo:

Sobre a epidemia - e tudo o que eu posso dizer pra vocês sobre isso vem do Governo Federal após consultas com os especialistas do Instituto Robert Koch e outros cientistas e virologistas: pesquisas estão sendo conduzidas ao redor do mundo sob alta pressão, mas ainda não há uma terapia nem uma vacina contra o coronavírus.

No que tange a este tema, há apenas uma coisa que nós podemos fazer, que é desacelerar a disseminação do vírus, esticar isso por meses e ganhar tempo. Tempo para pesquisas e para o desenvolvimento de remédios e vacinas. Mas, principalmente, tempo para que aqueles que ficarem doentes possam receber o melhor cuidado possível. (O DISCURSO..., 2020).

Bolsonaro, por sua vez, até abre espaço para falar da ciência, mas, como em seu discurso de campanha, coloca "Deus acima de tudo" (PRONUNCIAMENTO..., 2020) e não parece ajudar os cientistas e pesquisadores com a sua fala, já tentando demonstrar que há um tratamento em curso para o vírus: 
Enquanto estou falando, o mundo busca um tratamento para a doença. O FDA americano e o Hospital Albert Einsten, em São Paulo, buscam a comprovação da eficácia da cloroquina no tratamento do Covid-19. Nosso governo tem recebido notícias positivas sobre este remédio fabricado no Brasil e largamente utilizado no combate à malária, (sic) lúpus e artrite. Acredito em Deus, que capacitará cientistas e pesquisadores do Brasil e do mundo na (sic) cura desta doença. (PRONUNCIAMENTO..., 2020).

Há aqui um claro descompasso entre os dois líderes no que diz respeito à conduta no enfrentamento do coronavírus. Merkel faz um discurso de apoio à ciência e também demonstra que os alemães têm uma conduta diferente à dos brasileiros. Não há nenhuma conotação religiosa em sua fala, não há mágica ou misticismo. No caso do presidente do Brasil, há claramente o intuito de colocar a fé como algo importante, algo que é observável no país como um todo. A religião é um dado cultural muito forte, assim como o sincretismo nessa mesma área, o que faz com que mágica e misticismo também estejam presente no imaginário brasileiro. Isso parece facilitar que soluções aparentemente mais fáceis e rápidas possam ser colocadas, como num 'passe de mágica'. A parte da população mais afeita a essa questão mística e religiosa vai aceitar essa postura com mais facilidade.

Outro ponto a ser ressaltado é o posicionamento na frente da câmera de cada um dos líderes. Merkel é enquadrada de perfil, mas não exatamente de lado. Ela parece estar numa posição confortável e fala com tranquilidade, mas com firmeza em determinados momentos, enfatizando frases ou palavras. Numa leitura semiótica rápida, passa a ideia de quem está segura com o que diz e que tenta trazer uma palavra de apoio e de atenção para o que está acontecendo no país, como uma líder que está se dirigindo à nação de uma "maneira incomum" (O DISCURSO..., 2020). Não parece ser, no entanto, seu primeiro pronunciamento em rede nacional pela a TV, além de seus discursos por ocasião do Ano Novo.

Logicamente, Merkel fez inúmeros outros discursos em diversas situações, mas esse pronunciamento certamente marca a sua trajetória, por ser fora do comum e também por sua gravidade. Ainda assim, foi bem aceito e até políticos da oposição elogiaram sua postura. Sua tranquilidade ao falar, mesmo que lendo o seu pronunciamento, faz com que seja facilmente entendida. Não se exalta e pouco mexe as mãos e a cabeça, olhando sempre para a câmera. São pontos que contam a seu favor na tentativa de se mostrar próxima e solidária.

Bolsonaro é enquadrado de frente. Uma postura em que se pode perceber que está de pé. Ele claramente lê o seu pronunciamento e ainda assim tropeça em algumas palavras. Seu posicionamento é de alguém que não parece poder se mover. Fica com as mãos apoiadas - possivelmente em uma mesa - e pouco se desloca, mexe somente a cabeça. Só ao final da fala pode-se perceber que uma das mãos se levanta, já no momento em que se despede. Como já dito, Bolsonaro não é afeito a discursos e à presença de câmeras durante suas falas. Fica mais à vontade em frente de seus apoiadores e longe das situações formais.

Nesse pronunciamento tenta passar alguma seriedade e não recorre muito ao uso de ironias - salvo quando se refere ao médico Drauzio Varela, sem citar diretamente seu nome. Assim, não sorri ou tenta ter uma postura mais relaxada. No entanto, há claramente um distanciamento para com o público. Sua postura não permite sentir nenhuma aproximação, nem mesmo quando sua fala aponta para algum tom mais intimista e conciliador. Na verdade, Bolsonaro não está acostumado a tratar as pessoas nesse tom. Talvez por isso a sua fala não transmita uma empatia.

O cenário usado para a fala do presidente não é muito amplo, com uso de um fundo azul e com as bandeiras do Brasil e do brasão da República, à esquerda da imagem e um painel de madeira ao fundo à direita, onde foi colocada a imagem de uma intérprete de llíngua de sinais brasileira. Parece muito acanhado em relação ao que Merkel usou, que é ampliado por uma janela atrás com uma vista de um prédio e de outras edificações, o céu azul e também duas bandeiras, da Alemanha e da União Europeia, à esquerda da imagem. Talvez até pelo tipo de enquadramento, um pouco mais lateral, a sensação é de um espaço maior 
no cenário usado pela chanceler alemã. Há também o uso de uma imagem mais aproximada, que na fala de Bolsonaro é mais frequente do que na de Merkel. Isso também faz com que se perceba essa diferença.

Outro aspecto a ser notado é o uso de cortes. Na fala de Merkel há apenas três, com duas aproximações e um recuo da imagem. Em sua fala, há pouca mobilidade de enquadramentos, remetendo a uma segurança daquilo que se diz. No discurso de Bolsonaro, o que pode ainda contribuir para o seu tom vacilante, há oito cortes de imagem. Isso se deve a opções de quem edita o material ou por erros de gravação, que podem até ter sido causados por falhas do presidente em sua fala que determinem um corte. Esses pontos ressaltam ainda mais o que já foi dito em relação à postura calma de Merkel para falar e à vacilação e à dificuldade de Bolsonaro em pronunciamentos.

Cenários e enquadramentos também podem dizer muito sobre os dois líderes, além das palavras e do uso de certas metáforas, como as que Bolsonaro usa para falar do enfrentamento do vírus como numa situação de guerra. Apesar de Merkel dizer em sua fala que a situação na Alemanha era a mais grave desde a Segunda Guerra Mundial, ela não se aproveita da comparação para continuar falando de "combate ao vírus", "vitória sobre a pandemia" (PRONUNCIAMENTO..., 2020) ou algo do tipo, como faz Bolsonaro. Sua argumentação segue uma outra lógica, como o seu enquadramento no pronunciamento também parece fazer. Ela não se coloca de frente para a câmera e também consegue se colocar "ao lado" (O DISCURSO..., 2020) do cidadão alemão. Bolsonaro já se coloca de frente, numa postura mais direta, de líder falando a seus comandados.

O cenário mais amplo, conseguido pelo enquadramento de Merkel também sugere um tom mais de conversa, como alguém que está num espaço ampliado. Um cenário mais acanhado em termos de espaço pode levar a uma sinalização de algo mais contido, fechado, pouco afeito a agregar as pessoas. Numa comparação, há muitos programas de entrevistas que se utilizam desse cenário mais ampliado e com enquadramentos mais laterais do que de frente para colocar o entrevistado em cena e, de certa forma, também o espectador na conversa.

O cenário menos aberto de Bolsonaro sugere um local em que se coloca apenas uma pessoa para falar. Pouco se pode ver do fundo ou de espaços laterais. Isso não se parece com um convite à conversa, ao diálogo, mas remete mais a um pronunciamento bem formal de alguém falando para que os outros apenas ouçam, com um distanciamento entre orador e plateia.

Isso pode implicar que as pessoas que viram o discurso de Merkel tenham ainda uma maior sensação de acolhimento, além de um entendimento mais claro de que a líder estava ali se colocando próxima, mais junto de seus cidadãos. A comunicação se dá nesse tom e pode até mesmo funcionar melhor, reforçando, para os alemães, o que os profissionais de saúde estavam passando no que se refere à postura para enfrentar a pandemia.

Já o pronunciamento mais característico do líder falando à nação de um cenário menos aberto e com uma postura mais distanciada pode levar a um entendimento de que há uma ordem, inclusive por conta do tom militar e bélico colocado, que deve ser acatada por todos os que 'seguem' Bolsonaro. Isso aparece inclusive nas observações de que ele faz discursos mais para seus aliados e pouco para a nação como um todo. Algo que pode dificultar exatamente um entendimento geral da população, ainda mais num momento em que o presidente brasileiro enfrentava uma queda de popularidade que se deu ao longo de seu primeiro ano de governo.

Alguns dias depois de seu pronunciamento, Merkel se colocou em quarentena porque teve contato com um médico infectado por Covid-19. Passou 14 dias isolada e só voltou a trabalhar depois que três testes que fez deram negativo (ANGELA..., 2020). Bolsonaro teve vários de seus assessores infectados após uma viagem aos Estados Unidos. Fez três testes, disse que não tinha o vírus, logo depois do primeiro resultado, e saiu diversas vezes de sua residência, inclusive para cumprimentar pessoas e andar no meio daqueles que se aglomeravam nas ruas, em Brasília. Depois de confirmada a sua infecção pelo vírus, andou de moto 
pelos jardins do Palácio do Alvorada e falou com funcionários sem máscara, desrespeitando o isolamento. Tirou dois ministros da Saúde do cargo por discordar deles quanto a tratamentos da Covid-19 e à questão do isolamento social; em seguida, nomeou um general do Exército.

\section{CONSIDERAÇÕES FINAIS}

Se Alemanha, Nova Zelândia, Brasil ou Estados Unidos estão atravessando melhor ou pior a pandemia em comparações diretas entre os quatro países ou mesmo em relação a outras nações, isso não é o principal da análise feita aqui. Não se trata de verificar efeitos dos discursos, falas e posturas dos chefes de Estado, mas muito mais de observar como eles se colocam para o público e como demonstram a maneira com que o vírus deve ser enfrentado.

Não dá para fazer análises sobre a pandemia neste momento em que este artigo está sendo escrito, já que ainda há pessoas morrendo de Covid-19 em várias partes do mundo e que seria um tanto antecipado fazer juízos de valor sobre a atuação dos países. No entanto, neste momento, pode-se focar justamente na postura dos seus líderes. Como cada um deles se comporta diante de seu povo.

Claramente, há uma discrepância em relação ao comportamento dos quatro selecionados para esta análise. Merkel está preocupada em alertar a população para o perigo da doença e sobre o seu avanço, buscando um tom de entendimento e de ação conjunta para montar uma estratégia de oposição ao avanço do vírus. Ardern adotou a postura de erradicar o vírus da Nova Zelândia e não mede esforços para tal. A primeira-ministra já falou em volta à normalidade pós-pandemia, com 22 mortes confirmadas no final de julho de 2020. Trump prefere arrumar inimigos para culpar e pouco fala do seu próprio país como epicentro da doença, com mais de 153 mil mortes e mais de 4 milhões de infectados em 31 de julho de 2020. Bolsonaro também vai nessa direção, na maioria das vezes, negando a doença ou minimizando seus efeitos, mesmo com mais de 92 mil mortos e mais de 2,5 milhões de casos de pessoas contaminadas, em 31 de julho de 2020.

Sobre as falas em pronunciamentos, ainda que o presidente brasileiro busque um tom de união de esforços e de otimismo, há um discurso bastante potente de descaracterizar a pandemia ao considerá-la algo pouco grave, pouco "sério", se quisermos usar o termo utilizado por Merkel (O DISCURSO..., 2020). A utilização do próprio exemplo para tratar da doença como algo que não teria nenhum problema para si mesmo também faz de Bolsonaro uma pessoa que parece pouco preocupada com os demais e com a coletividade.

Em determinados momentos, o que parece que deve ser contido não é o vírus, mas outros elementos que aparecem bastante no discurso: o pânico e a histeria. A preocupação recai mais na economia do que na saúde das pessoas, visto que a ideia é a de uma "gripezinha" (PRONUNCIAMENTO..., 2020), e que as pessoas devem continuar trabalhando, sem tanta preocupação, pois tudo deve "voltar à normalidade" (PRONUNCIAMENTO..., 2020), ainda que não se tenha nenhuma segurança sobre o que seria esta normalidade num cenário tão pouco claro em meio a uma doença que não se conhece bem e que se alastra rapidamente.

Já Merkel desconfia dessa normalidade. Não existe, na visão dela, uma certeza sobre o que virá, mas nem por isso se pode dizer que ela faça um discurso pessimista. A postura parece ser de alguém que tenta ser realista, sem ser catastrófica. Não é um discurso para causar "pânico", se formos pensar no termo usado por Bolsonaro (PRONUNCIAMENTO..., 2020), mas também não se trata de dizer que está tudo bem e que logo a pandemia vai passar.

Essas posturas diferentes diante das câmeras também refletem na maneira como os discursos são recebidos. Se há elogios à alemã, até por parte de opositores, no caso do brasileiro, este foi um dos discursos que promoveram mais o distanciamento com uma grande parcela da população. $\mathrm{O}$ ato de se bater panelas 
durante seus pronunciamentos só se fez aumentar nos tempos de pandemia. Não se pode também deixar de notar o espanto dos telespectadores quando ele trata da doença como "gripezinha" (PRONUNCIAMENTO..., 2020) e fala que se deve voltar à normalidade, como se as pessoas não precisassem do isolamento social.

O discurso de Merkel é um marco histórico pelo ineditismo e pela relevância. Fez-se necessário e ela foi bem direta no que queria dizer. Já o mesmo não se pode dizer de Bolsonaro. O presidente brasileiro não se adequa ao formato do pronunciamento televisivo. Sua postura denuncia sua dificuldade com o momento e com as próprias palavras que deve proferir. Indica um caminho, seguir o ministro Mandetta e as recomendações do Ministério da Saúde, mas faz críticas ao isolamento social, dá mais importância à economia que à pandemia e ainda propaga o uso de um medicamento sem eficiência comprovada. $\mathrm{O}$ que deveria ser um serviço de orientação à nação mais parece um desserviço à mesma.

As dificuldades da Alemanha e do Brasil para enfrentarem a pandemia do coronavírus não devem ser vistas como apenas casos de saúde pública. Há muito a se pensar depois de ouvidos e vistos os dois discursos e a postura de quem os proferiu. Não se pode dizer que os caminhos de cada país se deram apenas por atitudes de seus gestores de saúde e de sua população.

\section{REFERÊNCIAS}

AGÊNCIA O GLOBO. Bolsonaro chega ao fim do $1^{\circ}$ ano com avaliação pior que Lula, Dilma e FHC. Exame, São Paulo, 08 dez. 2019. Brasil. Disponível em: https://exame.com/brasil/bolsonaro-chega-ao-fim-do-1o-anocom-avaliacao-pior-que-lula-dilma-e-fhcl. Acesso em: 14 maio 2020.

AGRELA, Lucas. Maioria dos casos graves da covid-19 são de pessoas entre 30 e 90 anos. Exame, São Paulo, 26 mar. 2020. Ciência. Disponível em: https://exame.com/ciencia/maioria-dos-casos-graves-da-covid19-sao-de-pessoas-de-30-a-90-anos/. Acesso em: 14 maio 2020.

ALEMANHA enfrenta maior desafio desde Segunda Guerra, diz Merkel. Deutsche Welle Brasil, [s. I.], 18 mar. 2020. Alemanha. Disponível em: https://www.dw.com/pt-br/alemanha-enfrenta-maior-desafio-desde-segundaguerra-diz-merkel/a-52830391. Acesso em: 30 abr. 2020.

ANGELA Merkel encerra quarentena após testar negativo para coronavírus. GaúchaZH, Porto Alegre, 03 abr. 2020. Saúde. Disponível em: https://gauchazh.clicrbs.com.br/saude/noticia/2020/04/angela-merkel-encerraquarentena-apos-testar-negativo-para-coronavirus-ck8k38hxx00cx01Ilw3b01yaa.html. Acesso em: 14 maio 2020.

BRANT, Danielle. Bolsonaro segue passos de Trump e adota rede social para discursar. Folha de S.Paulo, São Paulo, 03 nov. 2018. Poder. Disponível em: https://www1.folha.uol.com.br/poder/2018/11/bolsonarosegue-passos-de-trump-e-adota-rede-social-para-discursar.shtml. Acesso em 10 fev. 2021.

CHAZAN, Guy. Com $1^{\circ}$ pronunciamento na TV em 14 anos, Merkel mostra que a líder europeia está de volta. Tradução de Luiz Roberto Mendes Gonçalves. Folha de S.Paulo, São Paulo, 29 mar. 2020. Mundo. Disponível em: https://www1.folha.uol.com.br/mundo/2020/03/com-10-pronunciamento-na-tv-em-14-anosmerkel-mostra-que-a-lider-europeia-esta-de-volta.shtml. Acesso em 20 maio 2020.

CIOCCARI, Deysi; PERSICHETTI, Simonetta. A campanha eleitoral permanente de Jair Bolsonaro: o deputado, o candidato e o presidente. Lumina, Juiz de Fora, v. 13, n. 3, set.-dez. 2019, p.135-151. Disponível em: https://periodicos.ufjf.br/index.php/lumina/article/view/28571/20024. Acesso em: 10 fev. 2021

CORONAVÍRUS (COVID-19) gráficos e estatísticas. TradingView, [s. I.: s. n.], c2021. Disponível em: https:/l br.tradingview.com/covid19/. Acesso em: 04 ago. 2020.

DEMISSÃO de Mandetta é reprovada por $64 \%$ dos brasileiros, aponta Datafolha. O Globo, Rio de Janeiro, 17 abr. 2020. Brasil. Disponível em: https:/loglobo.globo.com/brasil/demissao-de-mandetta-reprovada-por-64-dosbrasileiros-aponta-datafolha-24379996. Acesso em: 14 maio 2020.

O DISCURSO histórico de Angela Merkel contra o coronavírus. Brasil247, [s. I.], 19 mar. 2020. Mundo. Disponível em: https://www.brasil247.com/mundo/o-discurso-historico-de-angela-merkel-contra-o-coronavirus. Acesso em: 20 maio 2020. 
DRAUZIO: 'Esquece sua vida normal, vai demorar muito tempo para voltar'. VivaBem, São Paulo, 02 abr. 2020. Saúde. Disponível em: https://www.uol.com.br/vivabem/noticias/redacao/2020/04/02/drauzio-esquecesua-vida-normal-vai-demorar-muito-tempo-pra-voltar.htm. Acesso em: 14 maio 2020.

FERRARI, Carla Montuori; OLIVEIRA, Luiz Ademir de; MARTINS, Thamiris Franco; CHAIA, Vera. Campanha permanente e espetacularização política: análise das estratégias narrativas de João Doria (PSDB) na fanpage. Líbero, São Paulo, v. 20, n. 40, jul.-dez. 2017, p. 54-64. Disponível em: http://seer.casperlibero.edu.br/index. php/libero/article/view/906. Acesso em 21 maio 2020.

FREIRE, Sabrina. Bolsonaro fez 70 lives em 2020; Jorge Seif e Gilson Machado participaram mais. Poder 360, [s. I.], 01 jan. 2021. Disponível em: https://www.poder360.com.br/governo/bolsonaro-fez-70-lives-em2020-jorge-seif-e-gilson-machado-participaram-maisl. Acesso em 10 fev. 2021.

GIL, Tamara. Coronavírus: como os EUA, com mais de 245 mil casos, se tornaram novo epicentro da pandemia de covid-19. UOL, São Paulo, 03 abr. 2020. Coronavírus. Disponível em: https://noticias.uol.com.br/ ultimas-noticias/bbc/2020/04/03/coronavirus-como-os-eua-se-tornaram-novo-centro-da-pandemia-de-covid-19. htm. Acesso em: 22 abr. 2020.

GOMES, Pedro Henrique. 'Não sou coveiro, tá?', diz Bolsonaro ao responder sobre mortos por coronavírus. G1, Rio de Janeiro, 20 abr. 2020. Política. Disponível em: https://g1.globo.com/politica/noticia/2020/04/20/naosou-coveiro-ta-diz-bolsonaro-ao-responder-sobre-mortos-por-coronavirus.ghtml. Acesso em: 23 abr. 2020.

INGRID, Gabriela. Clima tropical não protege contra o coronavírus, como disse Bolsonaro. VivaBem, São Paulo, 02 abr. 2020. Disponível em: https://www.uol.com.br/vivabem/noticias/redacao/2020/03/25/climatropical-nao-garante-protecao-de-coronavirus-como-disse-bolsonaro.htm. Acesso em: 14 maio 2020.

LAGO, Miguel. Bolsonaro fala outra língua. Piauí, São Paulo, 13 ago. 2018. Colunistas. Disponível em: https:// piaui.folha.uol.com.br/bolsonaro-fala-outra-lingual. Acesso em: 10 fev 2021.

LEMOS, José Alberto. Trump, um presidente em campanha permanente que mina a influência dos EUA. Rádio Renascença, Lisboa, 08 nov. 2017. Análise. Disponível em: https://rr.sapo.pt/2017/11/08/cronicasda-america/trump-um-presidente-em-campanha-permanente-que-mina-a-influencia-dos-eua/noticia/97716/. Acesso em: 21 maio 2020.

MANDETTA diz que escreve livro e que só a Casa Grande grita contra a quarentena. Brasil247, [s. I.], 21 abr. 2020. Geral. Disponível em: https://www.brasil247.com/geral/mandetta-diz-que-escreve-livro-e-que-so-a-casagrande-grita-contra-a-quarentena. Acesso em 23 de abril de 2020.

MARINS, Carolina; AMORIM, Felipe; MATTOS, Rodrigo. Registros e falta de autópsia indicam mais mortos do que índice oficial. UOL, São Paulo, 04 abr. 2020. Coronavírus. Disponível em: https://noticias.uol.com.brl saude/ultimas-noticias/redacao/2020/04/04/coronavirus-subnotificacao-mortes.htm. Acesso em: 22 abr. 2020.

MAZUI, Guilherme. Mandetta anuncia em rede social que foi demitido por Bolsonaro do Ministério da Saúde. G1, Rio de Janeiro, 16 abr. 2020. Política. Disponível em: https://g1.globo.com/politica/noticia/2020/04/16/ mandetta-anuncia-em-rede-social-que-foi-demitido-do-ministerio-da-saude.ghtml. Acesso em: 21 maio 2020.

MENON, Praveen. Nova Zelândia diz que erradicou coronavírus e suspende restrições. Agência Brasil, Rio de Janeiro, 08 jun. 2020. Internacional. Disponível em: https://agenciabrasil.ebc.com.br/internacional/ noticia/2020-06/nova-zelandia-diz-que-erradicou-coronavirus-e-suspende-restricoes. Acesso em: 04 ago. 2020.

MINISTRO das Relações Exteriores afirma que coronavírus é um plano comunista. G1, São Paulo, 22 abr. 2020. Jornal Nacional. Disponível em: https://g1.globo.com/jornal-nacional/noticia/2020/04/22/ministro-dasrelacoes-exteriores-afirma-que-coronavirus-e-um-plano-comunista.ghtml. Acesso em: 23 abr. 2020.

MÜLLER, Enrique. Merkel anuncia que deixará de ser chanceler ao término do atual mandato. El País, São Paulo, 29 out. 2018. Internacional. Disponível em: https://brasil.elpais.com/brasil/2018/10/29/ internacional/1540804961 805054.html. Acesso em: 10 fev. 2021.

PAULA, Carolina de. A crise dos Poderes e a campanha permanente do Presidente. IREE - Instituto para Reforma das Relações entre Estado e Empresa, [s. I.], c2019. Colunistas. Disponível em: https://iree.org. br/a-crise-dos-poderes-e-a-campanha-permanente-do-presidentel. Acesso em: 21 maio 2020. 
POLITO, Reinaldo. No teleprompter, Bolsonaro se parece com uma criança aprendendo a ler. UOL, São

Paulo, 27 ago. 2019a. Economia. Disponível em: https://economia.uol.com.br/blogs-e-colunas/coluna/reinaldopolito/2019/08/27/bolsonaro-uso-teleprompter.htm. Acesso em 10 fev. 2021.

POLITO, Reinaldo. Três erros de comunicação cometidos por Bolsonaro que você pode evitar. UOL, São Paulo, 02 maio. 2019b. Disponível em: https://economia.uol.com.br/blogs-e-colunas/coluna/reinaldopolito/2019/02/05/bolsonaro-erros-comunicacao-expressao-corporal-pausas-diccao.htm. Acesso em 10 fev. 2021.

PRONUNCIAMENTO do presidente da República, Jair Bolsonaro (24/03/2020). [Brasília, DF: s. n.], 2020.1 vídeo (4:56 min). Publicado pelo canal Planalto. Disponível em: https://www.youtube.com/watch?v=VI_DYbXaAE. Acesso em: 20 maio 2020.

REUTERS. Jacinda Ardern se torna premiê mais popular da Nova Zelândia em um século. G1, Rio de Janeiro, 19 maio 2020. Mundo. Disponível em: https://g1.globo.com/mundo/noticia/2020/05/19/jacinda-ardern-se-tornapremie-mais-popular-da-nova-zelandia-em-um-seculo.ghtml. Acesso em: 04 ago. 2020.

ROSSI, Marina. Hidroxicloroquina, tratamento experimental e arma na "guerra cultural" de Bolsonaro e Trump. El País, São Paulo, 08 abr. 2020. Pandemia de Coronavírus. Disponível em: https://brasil.elpais.com/ politica/2020-04-09/hidroxicloroquina-o-tratamento-experimental-contra-a-covid-19-que-virou-a-muleta-politicade-bolsonaro-e-de-trump-na-crise.html. Acesso em: 14 maio 2020.

VEGA, Miguel Ángel García. Como será a economia após o coronavírus. El País, São Paulo, 13 abr. 2020. Disponível em: https://brasil.elpais.com/economia/2020-04-13/como-sera-a-economia-apos-o-coronavirus.html. Acesso em: 21 maio 2020.

VEJA frases de Bolsonaro durante a pandemia do novo coronavírus. G1, Rio de Janeiro, 30 abr. 2020. Política. Disponível em: https://g1.globo.com/politica/noticia/2020/04/30/veja-frases-de-bolsonaro-durante-a-pandemiado-novo-coronavirus.ghtml. Acesso em: 30 abr. 2020. 